\section{Eficacia de una medida preventiva para el niño con riesgo cariogénico asocia- da a la estabilidad de pH salival}

Effectiveness of a preventive measure for children with cariogenic risk associated to salivary $\mathrm{pH}$ stability

\begin{abstract}
Resumen
Un factor etiológico de caries es la saliva, que estabiliza el $\mathrm{pH}$ por su concentración de carbonatos y fosfatos. Cuando la higiene oral es deficiente, el $\mathrm{pH}$ es ácido y óptimo para desmineralizar las superficies dentarias. Si predomina una dieta rica en azúcares y harinas, se acidifica más y el riesgo de iniciar caries es inminente.

Para determinar el comportamiento del $\mathrm{pH}$ salival y evidenciar la efectividad del cepillado como medida de prevención de bajo costo, eficaz y de fácil aplicación en niños con riesgo cariogénico se tomó muestras de saliva de 44 niños entre 6 y 8 años de San Martín de Porres, antes y después del desayuno, medidos con un potenciómetro; en GRUPO 1: con placa bacteriana antigua (sin cepillado previo) y GRUPO 2: con placa bacteriana reciente (con cepillado previo).

Según la prueba $\mathrm{t}$ de Student, la variación del $\mathrm{pH}$ salival, en ambos grupos, fue estadísticamente significativa $(\mathrm{p}=0.000)$ pero al comparar el grupo 1 y 2 no existieron diferencias estadísticamente significativas. Se concluye que la remoción de la placa bacteriana tanto antigua como reciente es una medida preventiva esencial que no está relacionada a la variación del $\mathrm{pH}$ salival.
\end{abstract}

\begin{abstract}
Saliva is an etiological factor of caries. It acts stabilizing $\mathrm{pH}$ by its concentration of carbonates and phosphates. When the oral hygiene is deficient, $\mathrm{pH}$ becomes acid and optimal for the demineralization of teeth surfaces. If a diet rich in sugars and flour predominates, they become more acid and the risk of caries beginning is imminent. To determinate the behavior of salivary $\mathrm{pH}$ and demonstrate the effectiveness of the brushing as a low cost, efficient, easy application prevention measure, in children with cariogenic risk, samples of saliva of 44 children between 6 and 8 were taken, from San Martin de Porres district, before and after breakfast and analyzed with a potentiometer. GROUP 1: with old bacterial plaque (without previous tooth brashing) and GROUP 2: with recent bacterial plaque (with previous tooth brushing). According to " $\mathrm{t}$ " test analysis, the variation of $\mathrm{pH}$ salivary in both groups, before and after foods was statistically significant $(p=0.000)$ but when comparing it between both groups 1 and 2 , statistically significant differences did not exist. The removal of old and recent bacterial plaque is an essential preventive measure that is not related to the variation of $\mathrm{pH}$ salivary.
\end{abstract}

Margot Gutiérrez llave', Lita Ortiz Fernández ${ }^{1}$, Katia Medina Calderón' ${ }^{1}$, Sylvia Chein Villacampa'.

Departamento Académico de Estomatología Biosocial. Facultad Odontología. UNMSM

Correspondencia:

Mg. Margot Gutiérrez Ilave Facultad Odontología, UNMSM Av. Germán Amézaga s/n, Lima, 1 Perú. e-mail: margoti11@yahoo.es

Palabras clave: Riesgo cariogénico, $\mathrm{pH}$ salival, capacidad buffer, higiene oral

Key words: Cariogenic risk, salivary $\mathrm{pH}$ capacity buffer, oral hygiene

\section{Introducción}

La caries dental es una enfermedad multifactorial, en la cual uno de los factores predisponentes e influyentes para desarrollarla es la acumulación de placa bacteriana y su consecuente variación del $\mathrm{pH}$ salival. ${ }^{1}$ Cuando no hay alimento, el $\mathrm{pH}$ permanece relativamente constante; al ingresar alimentos, este disminuye según el tipo de sustrato consumido (menor a 5.5 se considera crítico). ${ }^{2}$

La saliva mantiene y protege la integridad de la mucosa bucal, participa en la protección de los dientes gracias a su composición química, que le confiere un efecto tampón y contiene los iones necesarios para la remineralización. ${ }^{3}$ Además tiene capacidad antifúngica, antibacteriana y antiviral, necesarias para el mantenimiento del equilibrio de la microbiota oral. ${ }^{4}$ En los pacientes portadores de prótesis dental, facilita su adhesión a la mucosa.

La cantidad de flujo real de saliva es el resultado de la producción y consumo de saliva. La saliva en reposo es la que se produce de forma espontánea, en situación de relajación y en ausencia de estímulos exógenos o farmacológicos. La saliva estimulada es la que se obtiene después de haber sometido al paciente a estimulación salival. La secreción media de saliva mixta en reposo es de $0,2-0,4 \mathrm{ml} / \mathrm{min}$ y la de saliva estimulada es de $1-2 \mathrm{ml} / \mathrm{min}^{2}$

La saliva juega un papel importante en la higiene de la boca. Además de intervenir en el proceso digestivo, ayudando a la masticación y recubriendo los alimentos de enzimas que facilitan la transformación del almidón contenido 
en ellos, este líquido incoloro impide la proliferación de la placa bacteriana. Actúa estabilizando el $\mathrm{pH}$ de la boca, debido a su alta concentración en carbonatos y fosfatos. Si no se mantiene una higiene bucodental adecuada, prolifera gran cantidad de placa bacteriana y microorganismos, que hacen que el $\mathrm{pH}$ dentro de la boca se vuelva ácido. Una alimentación con excesivo contenido en azúcares refinados y harinas contribuye también a acidificar el pH bucal. ${ }^{8} \mathrm{Al}$ mismo tiempo, la saliva juega un papel esencial ya que incluye otros elementos como calcio y flúor que ayudan a remineralizar los dientes y mantener su esmalte. . $^{1,34}$

Una de las funciones relacionadas con la actividad de caries, es la capacidad Buffer de la saliva, la que se vincula con el contenido de bicarbonato-ácido carbónico; sirve para mantener el $\mathrm{pH}$ salival relativamente constante y así evita la acción desmineralizante de los ácidos sobre el esmalte ya que el $\mathrm{pH}$ cumple la función clave en el desarrollo de la microbiota bucal. El pH promedio salival es $\mathrm{de}^{6,7}$. Un $\mathrm{pH}$ bajo, llamado crítico (entre 4 y 5), favorecerá el desarrollo de microorganismos acidogénicos y acidúricos tales como estreptococos y lactobacilos. ${ }^{2,5}$

La tasa de secreción, así como el efecto tampón del pH, están relacionados con la caries dental usados en combinación con otros indicadores del incremento de riesgo de caries (s.mutans, lactobacilos, dieta, transtornos médicos), forman un instrumento muy útil en el diagnóstico de la actividad potencial de la caries y de la producción de riesgo de caries dental de un individuo. ${ }^{6}$

Velásquez y col (1993) establecieron la posible relación del $\mathrm{pH}$ salival con los hábitos bucales, dieta y placa bacteriana que puede influir en la presencia de caries dental en niños de 6 a 11 años de edad. Realizaron dos mediciones de $\mathrm{pH}$ salival antes y después del desayuno, mediante el uso de papel indicador para cuantificar el grado de acidez o alcalinidad. Se halló que el $\mathrm{pH}$ antes del desayuno fue de ${ }^{5,7} \mathrm{y}$ luego del desayuno de ${ }^{4,7}$; por lo que se concluye que una dieta cariogénica y la presencia de placa bacteriana se manifiesta en el valor de $\mathrm{pH}$ salival, el cual al tornarse ácido influye en la creación de caries dental. ${ }^{9}$

OLaya A y col (2002) determinaron el flujo, el pH y la actividad peroxidásica salival en un grupo de 82 niños escolares de ambos sexos, con edades comprendidas entre 7 y 11 años con diferentes grados de afectación por la caries dental. Encontraron una diferencia significativa para el $\mathrm{pH}$ salival, el que fue menor en el grupo más afectado por la caries dental. ${ }^{8}$

La caida del pH salival después del consumo de los alimentos constituye un factor que favorece a la formación de nuevas lesiones cariosas por ello, las medidas tendientes a evitar dicha variación son de utilidad.

La presente investigación pretende evidenciar la efectividad del cepillado como una medida de prevención de bajo costo, eficaz y de fácil aplicación, para la caries dental una patología de alta prevalencia, especialmente en niños de grupos etáreos de 6 a 12 años de edad y con riesgo cariogénico.

La hipótesis de trabajo fue: La caida del $\mathrm{pH}$ salival después de los alimentos es mayor en los niños con placa antigua (sin cepillado previo) en comparación con los niños con placa bacteriana reciente (con cepillado previo).

\section{Materiales y métodos}

La presente investigación fue un Ensayo Cuasi Experimental, de Cohorte y Longitudinal. La muestra estuvo constituída por 44 niños de ambos sexos con riesgo cariogénico entre 6 y 8 años de edad de una Institución Educativa Estatal de San Martín de Porres; formándose dos grupos de estudio: GRUPO 1: escolares con placa bacteriana antigua (sin cepillado previo desde el día anterior a la toma de muestra) y GRUPO 2: escolares con placa bacteriana reciente (con cepillado previo usando la técnica de Bass modificada y realizado por un investigador calibrado previamente). A ambos grupos se les indicó estar en ayunas previo a la primera toma de muestra de saliva no estimulada

Tabla No. 1: Estadísticos de muestras relacionadas para el grupo de escolares con placa bacteriana antigua (sin cepillado previo).

\begin{tabular}{l|c|c|c|c}
\hline \multicolumn{1}{c|}{ pH salival } & media & $\mathrm{n}$ & $\begin{array}{c}\text { desviación } \\
\text { típica }\end{array}$ & $\begin{array}{c}\text { error típico de } \\
\text { la media }\end{array}$ \\
\hline $\mathrm{pH}$ basal 1 & 7.4552 & 21 & .19485 & .04252 \\
$\mathrm{pH}$ final 1 & 7.1357 & 21 & .29330 & .06400 \\
\hline
\end{tabular}

Tabla No. 2: Prueba $t$ de Student de muestras relacionadas para el grupo de escolares con placa bacteriana antigua (sin cepillado previo)

\begin{tabular}{l|c|c|c}
\hline & $\mathrm{t}$ & $\mathrm{gl}$ & $\begin{array}{c}\text { significancia } \\
\text { (bilateral) }\end{array}$ \\
\hline $\mathrm{pH}$ basal 1 & & & \\
$\mathrm{pH}$ final 1 & 5.631 & 20 & .000 \\
\hline
\end{tabular}

(pH basal ) y se les proporcionó un desayuno con alimentos no cariogénicos después de la toma de muestra inicial. Después de 20 minutos, se tomó la segunda muestra de saliva no

Se recolectó las muestras de saliva según las recomendaciones de la Asociación Latinoamericana de Investigación en Saliva (ALAIS):

- No debe realizar ejercicio físico extenuante antes de la recolección.

- La saliva debe ser colectada a la misma hora del día, la recolección debe realizarse en un lugar tranquilo con suficiente luz.

paciente debe enjuagarse la boca y esperar 1 minuto antes de iniciar la recolección. Debe recolectarse la saliva usando un cronómetro.

- Las muestras que contengan sangre, o algún detrito deben descartarse.

Las muestras de saliva no estimulada fueron depositadas por el propio niño en unos vasitos descartables previamente esterilizados y clasificados de acuerdo al código asignado a cada niño según el grupo al que pertenecía antes y después del desayuno.

La lectura la realizó otro investigador previamente calibrado con el uso de un potenciómetro digital calibrado y limpiado con agua destilada en forma permanente (cada 3 lecturas).

\section{Resultados}

Del análisis de la variación del $\mathrm{pH}$ salival en el grupo de escolares con placa bacteriana antigua, luego de la aplicación de la Prueba T de Student (con un margen de error de $0,05 \%$ ), se observó que la variación fue estadísticamente significativa $(p=0.0000)$. estimulada ( $\mathrm{pH}$ final). 
Del análisis de la variación del pH salival en el grupo de escolares con placa blanda reciente, luego de la aplicación de la Prueba T de Student (con un

margen de error de $0,05 \%)$, se observó que la variación fue estadísticamente significativa $(\mathrm{p}=0.0000)$.

Tabla No. 3: Estadísticos de muestras relacionadas para el grupo de escolares con placa bacteriana reciente (con cepillado previo).

\begin{tabular}{l|c|c|c|c}
\hline \multicolumn{1}{c|}{$\mathrm{pH}$ salival } & media & $\mathrm{n}$ & $\begin{array}{c}\text { desviación } \\
\text { típica }\end{array}$ & $\begin{array}{c}\text { error típico de } \\
\text { la media }\end{array}$ \\
\hline $\mathrm{pH}$ basal 2 & 7.4878 & 23 & .19778 & .04124 \\
$\mathrm{pH}$ final 2 & 7.1909 & 23 & .18414 & .03840 \\
\hline
\end{tabular}

Tabla No. 4: Prueba $t$ de Student de muestras relacionadas para el grupo de escolares con placa bacteriana reciente (con cepillado previo).

\begin{tabular}{l|c|c|c}
\hline & $\mathrm{t}$ & $\mathrm{gl}$ & $\begin{array}{c}\text { significancia } \\
\text { (bilateral) }\end{array}$ \\
\hline $\mathrm{pH}$ basal 2 & & & \\
$\mathrm{pH}$ final 2 & 7.895 & 22 & .000 \\
\hline
\end{tabular}

Al comparar la variación del $\mathrm{pH}$ salival entre ambos grupos, luego de la aplicación de la Prueba T de Student

para muestras independientes, se observó que no existen diferencias significativas.

Tabla No. 5 . Prueba $t$ de Student de muestras independientes para el grupo de escolares con placa bacteriana antigua y reciente

\begin{tabular}{l|l|c|c|c}
\hline & & $\mathrm{t}$ & $\mathrm{gl}$ & $\begin{array}{c}\text { signifi- } \\
\text { cancia } \\
\text { (bilateral) }\end{array}$ \\
\hline $\begin{array}{l}\text { grupo placa antigua } \\
\begin{array}{l}\mathrm{pH} \text { basal 1) y (pH } \\
\text { final 1) }\end{array}\end{array}$ & $\begin{array}{l}\text { se asumen varianzas } \\
\text { iguales } \\
\text { no se asumen va- } \\
\text { rianzas iguales }\end{array}$ & .550 & 42 & .585 \\
\cline { 2 - 5 } $\begin{array}{l}\text { grupo placa reciente } \\
\text { (pH basal 2) y (pH } \\
\text { final 2) }\end{array}$ & $\begin{array}{l}\text { se asumen varianzas } \\
\text { iguales } \\
\text { no se asumen va- } \\
\text { rianzas iguales }\end{array}$ & .754 & 41.744 & .585 \\
\hline
\end{tabular}

\section{Discusión}

En el año 1993, Velásquez y col. establecieron la posible relación del $\mathrm{pH}$ salival con los hábitos bucales, dieta y placa bacteriana que puede influir en la presencia de caries dental en niños de 6 a 11 años de edad. Se halló que el $\mathrm{pH}$ antes del desayuno fue de 5,7 y luego del desayuno de 4,7; por lo que se concluye que una dieta cariogénica y la presencia de placa bacteriana influye en el valor de $\mathrm{pH}$ salival, el cual al tornarse ácido influye en la creación de caries dental.11 Si bien la metodología realizada en nuestra investigación no fue similar, los resultados coinciden en afirmar que la presencia de placa bacteriana está relacionada con los valores del $\mathrm{pH}$ salival.

Así como, el análisis de la variación de $\mathrm{pH}$ salival y otras características de la saliva, la formación y composición de la placa bacteriana constituyen factores de riesgo en la producción de la caries.

Por ello, son importantes las medidas preventivas, como la técnica, frecuencia y momentos del cepillado, para aplicarlas en grupos de niños en riesgo cariogénico. Se ha evidenciado, que ésta medida práctica, de bajo costo y eficaz, es sumamente importante en todos los grupos de riesgo sin importar su antigüedad.

Al término del estudio se llegó a las siguientes conclusiones:

- La variación de pH salival en placa antigua no tiene diferencia estadísticamente significativa en relación a la variación de $\mathrm{pH}$ salival en placa reciente.

- La remoción de la placa bacteriana tanto antigua como reciente es una medida preventiva esencial que no está relacionada a la variación del $\mathrm{pH}$ salival.

\section{Referencias bibliográficas}

1. Tylstrup A. Caries. España: Edit. Doyma, 1998:21-23.

2. Jenkins N.G. Fisiología y bioquímica bucal. México: Edit. Limusa, 1993:258-266.

3. Lozzari E.P. Bioquímica dental. Mexico: Edit. Interamericana, 1997:121-127

4. Liébana U. J. Microbiología oral. Madrid. España. Edit. Latinoamericana, 1995:43038.

5. Negroni M. Microbiología estomatológica. Fundamentos y guía práctica. Buenos Aires: Edit. Medica Panamericana, 1999:191-194.

6. Wolfe D.H. Química general orgánica y biológica. $2^{\mathrm{a}}$ ed. Colombia: Ediciones Mc Graw- Hill, 1998:179-188.

7. Navia J.M. Influencia de la nutrición en las glándulas salivales. Resumen del II Congreso Internacional de Investigación en Saliva. Facultad de Odontologia. Universidad Autónoma del Estado de México, 1996:37.

8. Olaya A., Delfin S., y col. Determinación del flujo, el PHy la actividad peroxidasica salival en niños con diferentes grados de caries dental. Instituto de ciencias médicas de la Habana. Revista Facultad de Estomatología, 2002.

9. Velásquez P.D., Rodríguez E. Relación del $\mathrm{pHSalival} \mathrm{con} \mathrm{la} \mathrm{caries} \mathrm{dental} \mathrm{en} \mathrm{un} \mathrm{grupo}$ de niños de 6 a 11 años. Univ. Odontol; 1993:12(24):59-63.

Recibido : 02-05-2007

Aceptado para publicación: 25-05-2007 